\title{
Modelling and Simulation of Mho Type Distance Relay for High Voltage Transmission Line Protection Using MATLAB Software
}

\author{
Win Win Tun \\ Department of Electrical Power \\ Engineering \\ Yangon Technological University \\ Yangon, Myanmar \\ winwintun5213@gmail.com
}

\author{
Ohn Zin Lin \\ Department of Electrical Power \\ Engineering \\ Yangon Technological University \\ Yangon, Myanmar \\ ohnzinlin@ytu.edu.mm
}

\author{
Han Su Yin \\ Department of Electrical Power \\ Engineering \\ Yangon Technological University \\ Yangon, Myanmar \\ hansuyin2009@gmail.com
}

\begin{abstract}
Transmission lines are an important part of a power system. Transmission lines have high power transmission capacity and they are prone to faults of larger magnitudes. Various faults occur in transmission lines. Therefore, protection relays are necessary to protect transmission lines. The purpose of protection system is to interrupt the faulty section from the healthy section because the fault currents may damage the electrical equipments. One of the protection relays is distance relay and it is mainly used in transmission line. Sometimes these relay are used for backup protection. Distance relays for determining the impedance need the voltage and current. Transmission lines are typically protected by distance protection relay. Distance relays are considered of high speed class and can provide transmission lines. Nowadays, numerical distance relays have been used instead of using electromechanical and static distance relays. The proposed model was verified under different tests such as single line to ground (L-G) fault, double line to ground (L-L-G) fault, line to line (L-L) fault and three phase (L-L-L) fault. SimPower System was used for modelling and simulation of distance relay, transmission lines and faults. The simulation results were obtained from MATLAB software shows the feasibility of analysis of transmission line protection with mho type distance relay for single line to ground fault, double line to ground fault, line to line fault and three phase fault at different location of transmission lines. The difficulties understanding on operation of distance relay can be cleared by using MATLAB/SIMULINK software.
\end{abstract}

Keywords - Distance relay, Single line to ground fault $(L-G)$, Double line to ground $(L-L-G)$, Line to Line fault $(L-L)$, Three phase fault (L-L-L), MATLAB/SIMULINK.

\section{INTRODUCTION}

An electrical power system is a network of electrical which transmission line, current transformer, voltage transformer, circuit breaker and power transformer, etc are included. When a fault occurs in power system, an abnormal large amount of current flows through the power system. These fault currents will damage the electrical components and will be unstable the power system. Therefore, power system protection is necessary to protect from fault condition to stable generation, transmission and distribution. Most of fault occur in transmission line of power system and these fault may be black out condition of the power system. Thus, transmission line protection need to protect the damaging of electrical equipments and to maintain the healthy system [1].
Distance protection scheme is widely used to protect high voltage transmission lines and sub-transmission lines. This relay is proportional to the line length and between relay location and the fault point. Distance relays have high speed fault clearance capabilities and more selective as compare with other protection relays. Mho type distance relays are directional in nature as it can identify the faults in the forward direction [2].

The basic principle of distance relay is based on the values of voltage and current and the relay operate the impedance between the relay terminal and the fault location. There are many types of distance relay such as mho relay, offset mho relay, admittance relay, reactance relay and impedance relay, etc. Every type of characteristics has different functions and theories behind [3]. Protection relays have a great impact on power system's reliability and stability and on the main components in power system. Distance relay or impedance relay can be used main protection or backup protection in transmission lines [4]. Nowadays, numerical distance relays have been used as replacing static distance relays and electromechanical distance relays [5]. The understanding on the operation of distance relay is quite difficult compared to other protection relays such as overcurrent relay, over or under voltage relay and over or under frequency relay etc due to its complex theories and philosophies[6].

In this paper, distance relay is modeled and simulated on the transmission lines. For this distance relay, fault detection block, impedance measurement block and zone protection coordination are created by using Matlab/simulink software. And then, mho type distance relay model is implemented and various faults are created on transmission line with mho type distance relay. The test system is selected $230 \mathrm{kV}$ KamanatSittaung transmission line and $230 \mathrm{kV}$ Sittaung-Thahtone transmission line. After distance relay is developed, single line to ground fault, double line to ground fault, line to line fault and three phase fault were created in model of transmission line with distance relay and then the results will be analyzed to study the behavior of developed mho type distance relay.

\section{PRotection THEORIES OF Distance RELAY}

Distance relays are generally used for medium and long transmission lines. These relays operate by using voltage and current phasors for impedance calculation whether the fault impedance is within zone of protection or not. Various faults 
such as single line to ground (L-G) fault, double line to ground (L-L-G) fault, line to line (L-L) fault and three phase (L-L-L) fault occur in transmission lines and these faults may damage electrical equipments. Thus, transmission line protection is an important role of power transmission lines. Distance relays are necessary seven units to select types of faults and these units detect types of fault which the fault occurred between the phase and phase or between phase and ground.

TABLE I. FAULT IMPEDANCE ALGORITHM FOR DIFFERENT TYPES OF FAULT

\begin{tabular}{|c|c|}
\hline Fault Calculation & Algorithm \\
\hline Phase A - Ground & $\mathrm{ZA}=\mathrm{VA} /(\mathrm{IA}+3 \mathrm{~K} 0 \mathrm{I} 0)$ \\
\hline Phase B - Ground & $\mathrm{ZB}=\mathrm{VB} /(\mathrm{IB}+3 \mathrm{~K} 0 \mathrm{I} 0)$ \\
\hline Phase C-Ground & $\mathrm{ZC}=\mathrm{VC} /(\mathrm{IC}+3 \mathrm{~K} 0 \mathrm{I} 0)$ \\
\hline $\begin{array}{l}\text { Phase A - B or A - B - } \\
\text { Ground }\end{array}$ & $\mathrm{ZAB}=\mathrm{VAB} /(\mathrm{IA}-\mathrm{IB})$ \\
\hline $\begin{array}{l}\text { Phase A - C or A - C - } \\
\text { Ground }\end{array}$ & $\mathrm{ZAC}=\mathrm{VAC} /(\mathrm{IA}-\mathrm{IC})$ \\
\hline Phase B - C or B - C - Ground & $\mathrm{ZBC}=\mathrm{VBC} /(\mathrm{IB}-\mathrm{IC})$ \\
\hline Phase A - B - C & $\begin{array}{l}\text { ZABC }=\text { VA/IA or VB/IB or } \\
\text { VC/IC }\end{array}$ \\
\hline
\end{tabular}

Table I shows fault impedance algorithm for different type of faults used to calculate the impedance at the relay location for different types of fault.

In Table I, A, B and C indicate the phase faults and $\mathrm{G}$ indicates the ground fault.

$\mathrm{VA}, \mathrm{VB}$ and $\mathrm{VC}$ are the phase voltages

IA, IB and IC are the phase currents

$\mathrm{Z}_{0}$ is zero sequence impedance

$\mathrm{Z}_{1}$ is positive sequence impedance

$\mathrm{K}_{0}$ is residual compensation factor where $\mathrm{K}_{0}=\left(\mathrm{Z}_{0}-\right.$

$\left.\mathrm{Z}_{1}\right) / \mathrm{KZ}_{1}$. $\mathrm{K}$ can be 1 or 3 depend on the relay design.

$\mathrm{I}_{0}=(\mathrm{Ia}+\mathrm{Ib}+\mathrm{Ic}) / 3$

Three zone protections are explained the following.

- Zone 1 setting is set that the zone setting is 80 to $85 \%$ of protected line and the remaining 15 or $20 \%$ is for some errors such as instruments and occurring of transient.

- Zone 2 setting is set that the zone setting is $120 \%$ to $150 \%$ of protected line or $100 \%$ of protected line in addition $50 \%$ of the shortest next line.

- Zone 3 setting is set that the zone setting is $120 \%$ of the sum of protected line and the longest line or $200 \%$ to $250 \%$ of protected line.

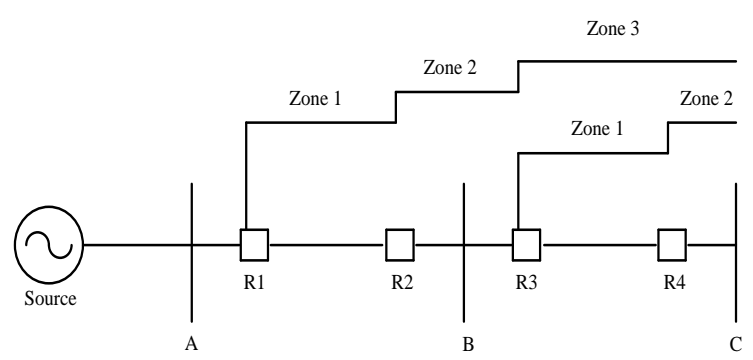

Fig. 1. Transmission line protection zones

The distance relay operates on the positive sequence impedance between relay and fault point for phase distance protection. The zero sequence impedance is for ground distance protection. The Fig. 1 shows the transmission line protection zones.

\section{III.DEVELOPMENT OF MHO TyPE DistANCE RELAy MODEL}

Different types of characteristic are presented on distance relay such as mho, offset mho, reactance, quadrilateral, admittance, polarized-mho, etc. Each one of characteristics has its own function and theories behind. The mho type distance relay operates when impedance of the fault enters into the operating characteristic of protection zone when the ratio of V/I fall inside a circle. Fig. 2 shows the characteristic of mho type distance relay which is described on the R-X plain. Fig. 3 shows flow chart for protection algorithm of mho type distance relay.

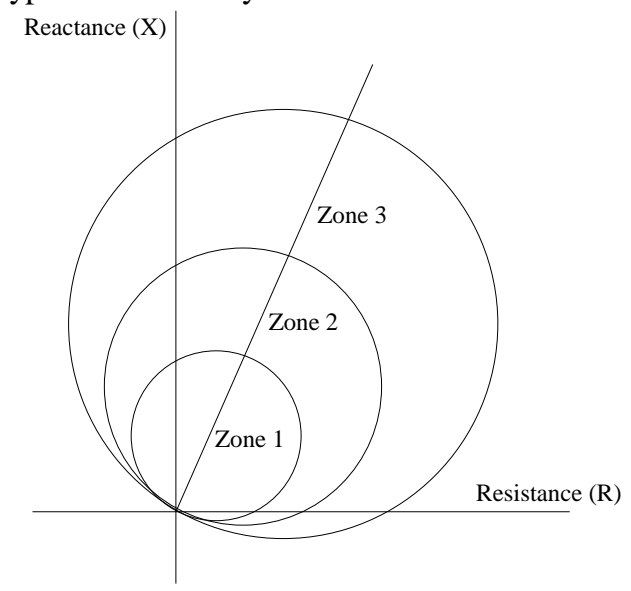

Fig. 2. Mho type distance relay characteristic

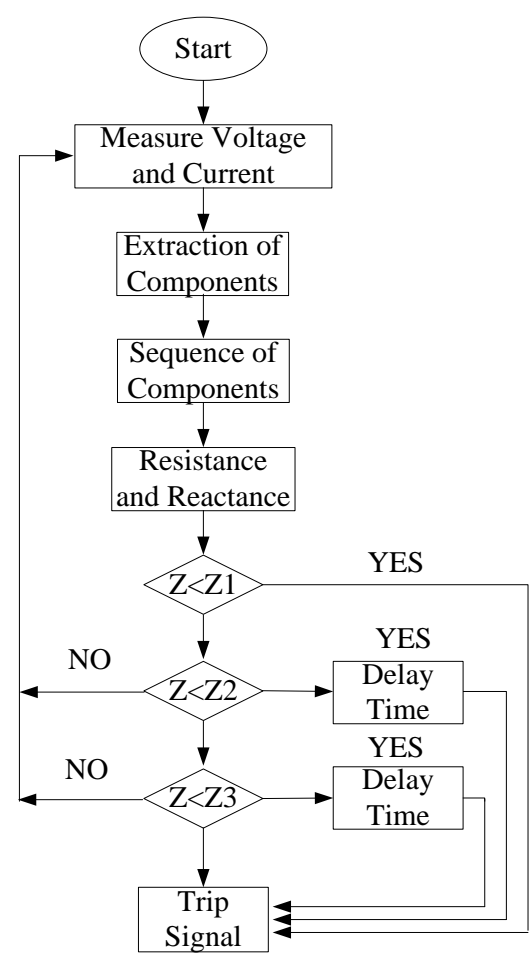

Fig. 3. Mho type distance relay Algorithm

In this paper, mho type distance relay is modelled and protection is developed for high voltage transmission line. The single line diagram for selected system is shown in Fig. 4 (a) and overall parameter of power transmission line is shown in table II. The selected systems are Kamanat-Sittaung transmission line and Sittaung-Thahtone transmission line. 
And then, transmission lines are modelled to analyse the behaviour of mho type distance relay installed in this transmission line. The Fig. 4 (b) shows the transmission line model without distance relay.

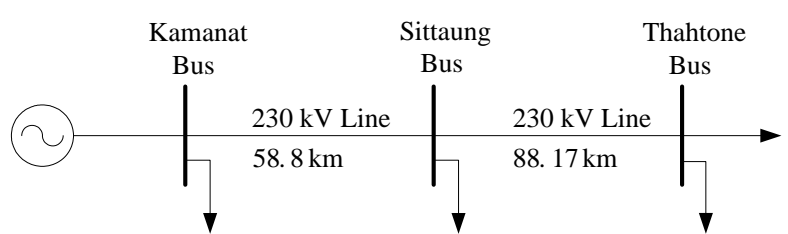

Fig. 4 (a). Single Line Diagram of High Voltage Transmission Line

TABLE II. PARAMETERS FOR HIGH VOLTAGE TRANSMISSION UNDER STUDY

\begin{tabular}{|l|l|l|}
\hline No & Parameters & Value \\
\hline 1 & Transmission Line Length 1 & $58.8 \mathrm{~km}$ \\
\hline 2 & Transmission Line Length 2 & $88.17 \mathrm{~km}$ \\
\hline
\end{tabular}

\begin{tabular}{|l|l|l|}
\hline 3 & Nominal Voltage & $230000 \mathrm{~V}$ \\
\hline 4 & Nominal Frequency & $50 \mathrm{HZ}$ \\
\hline 5 & Line Resistance ( R1 = R2 ) & $0.0474 \quad \Omega / \mathrm{km}$ \\
\hline 6 & Line Resistance ( R0 ) & $0.3073 \quad \mathrm{~km}$ \\
\hline 7 & Line Inductance( L1 = L2 ) & $0.001011047 \quad \mathrm{H} / \mathrm{km}$ \\
\hline $\mathbf{N o}$ & Parameters & Value \\
\hline 8 & Line Inductance( L0 ) & $0.003476000 \quad \mathrm{H} / \mathrm{km}$ \\
\hline 9 & Line Capacitance ( C1 = C2 ) & $0.0000000113 \mathrm{~F} / \mathrm{km}$ \\
\hline 10 & Line Capacitance ( C0 ) & $0.00000000814 \mathrm{~F} / \mathrm{km}$ \\
\hline 11 & Total Positive Sequence TL1 & $2.78712+\mathrm{j} 18.67650 \Omega$ \\
\hline 12 & Total Zero Sequence TL1 & $18.06924+\mathrm{j} 64.2106 \Omega$ \\
\hline 13 & Total Positive Sequence TL2 & $4.17925+\mathrm{j} 28.00534 \Omega$ \\
\hline 14 & Total Zero Sequence TL2 & $27.09464+\mathrm{j} 96.2831 \Omega$ \\
\hline
\end{tabular}

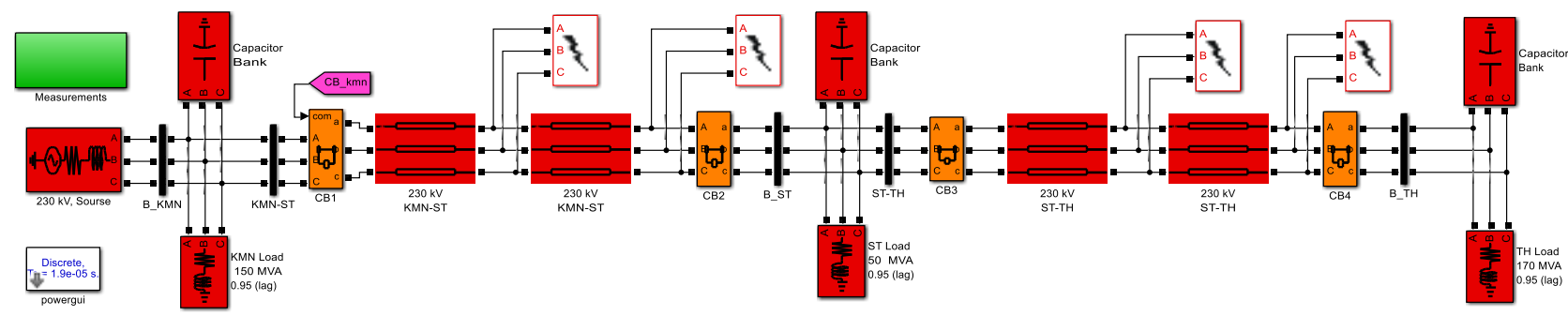

Fig. 4 (b). Simulation Model without Distance relay of High Voltage Transmission Line

\section{A. Development of Mho Type Distance Relay Model}

Mho type distance relay is implemented as shown in Fig. 5. The modelling system consists of (i) fault detection and classification, (ii) fault impedance calculation and (iii) zone determination. In this relay model, Fig. 6, Fig. 7 and Fig. 8 are illustrated for evaluated impedance of single line to ground fault, double line to ground fault/line to line fault and three phase fault using MATLAB/SIMULINK software.

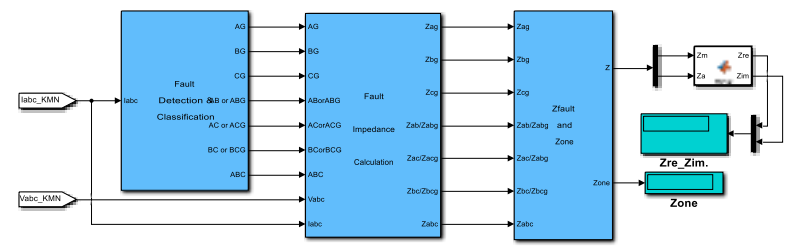

Fig. 5. Mho type Distance relay model

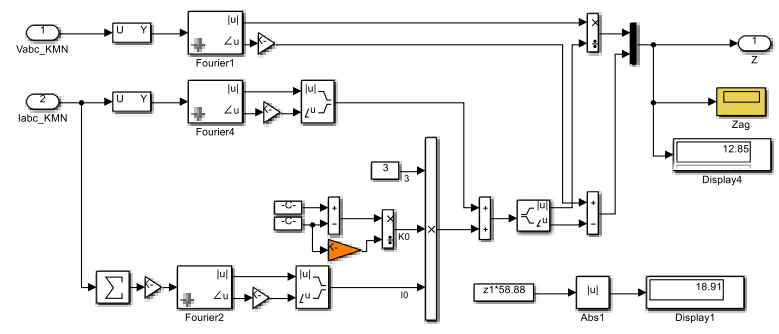

Fig. 6. Impedance calculation model for Single line to ground fault

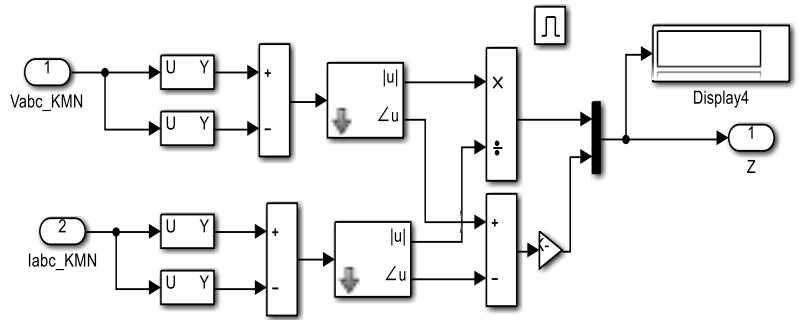

Fig. 7. Impedance Calculation Model for Double Line to Ground Fault /Line to Line Fault 
JAREE-Journal on Advance Research in Electrical Engineering

Volume3, Number 2, October 2019

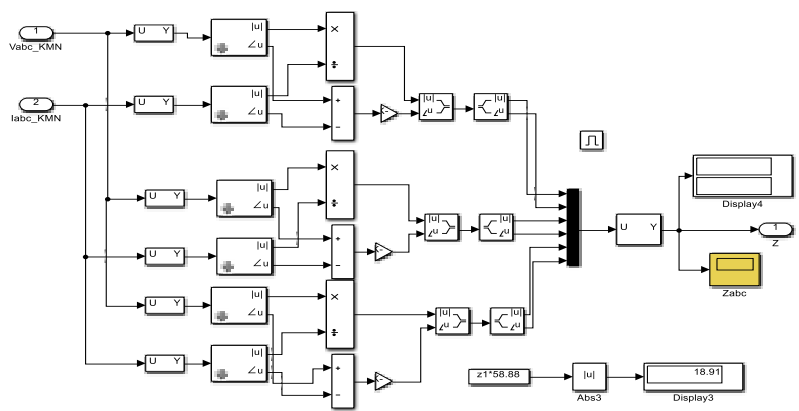

Fig.8. Impedance calculation model for three phase fault

B. Relay Setting Calculation for Zones of Protection for Mho Type Distance Relay

Line length $=58.8 \mathrm{~km}$

Resistance $=0.0474 \Omega / \mathrm{km}$

Reactance $=0.317629 \mathrm{H} / \mathrm{km}$

Impedance $=\mathrm{R}+\mathrm{jXL}$

$=0.0474+\mathrm{j} 0.317629 \Omega / \mathrm{km}$

Zone $1=80 \% \mathrm{X}(0.0474+\mathrm{j} 0.317629) \times 58.8$

$=2.229696+\mathrm{j} 14.941268$

$=15.106721 \angle 81.512^{\circ}$
Delay Time $=0 \mathrm{sec}$

Zone 2

$$
\begin{aligned}
& =120 \% \times(0.0474+\mathrm{j} 0.317629) \times 58.8 \\
& =3.344544+\mathrm{j} 22.411902 \\
& =22.660082 \angle 81.512^{\circ}
\end{aligned}
$$

Delay Time $=0.3 \mathrm{sec}$

$$
\begin{aligned}
\text { Zone } 3 & =225 \% \mathrm{X}(0.0474+\mathrm{j} 0.317629) \times 58.8 \\
& =6.271020+\mathrm{j} 42.022316 \\
& =42.48765 \angle 81.512^{\circ}
\end{aligned}
$$

Delay Time $=0.6 \mathrm{sec}$

\section{Model of High Voltage Transmission Line}

The simulation model for $230 \mathrm{kV}$ high voltage transmission lines with mho type distance relay protection scheme is shown in Fig. 9. Distance relay operates based on voltage and current values at Kamanat Bus. For simulation with fault, the fault resistance is set as $0.001 \Omega$ and ground resistance is set as $0.01 \Omega$. Different fault types are applied at various distances from Kamanat Bus for testing of three protection zones. The fault impedance and protection zone are described in this figure.

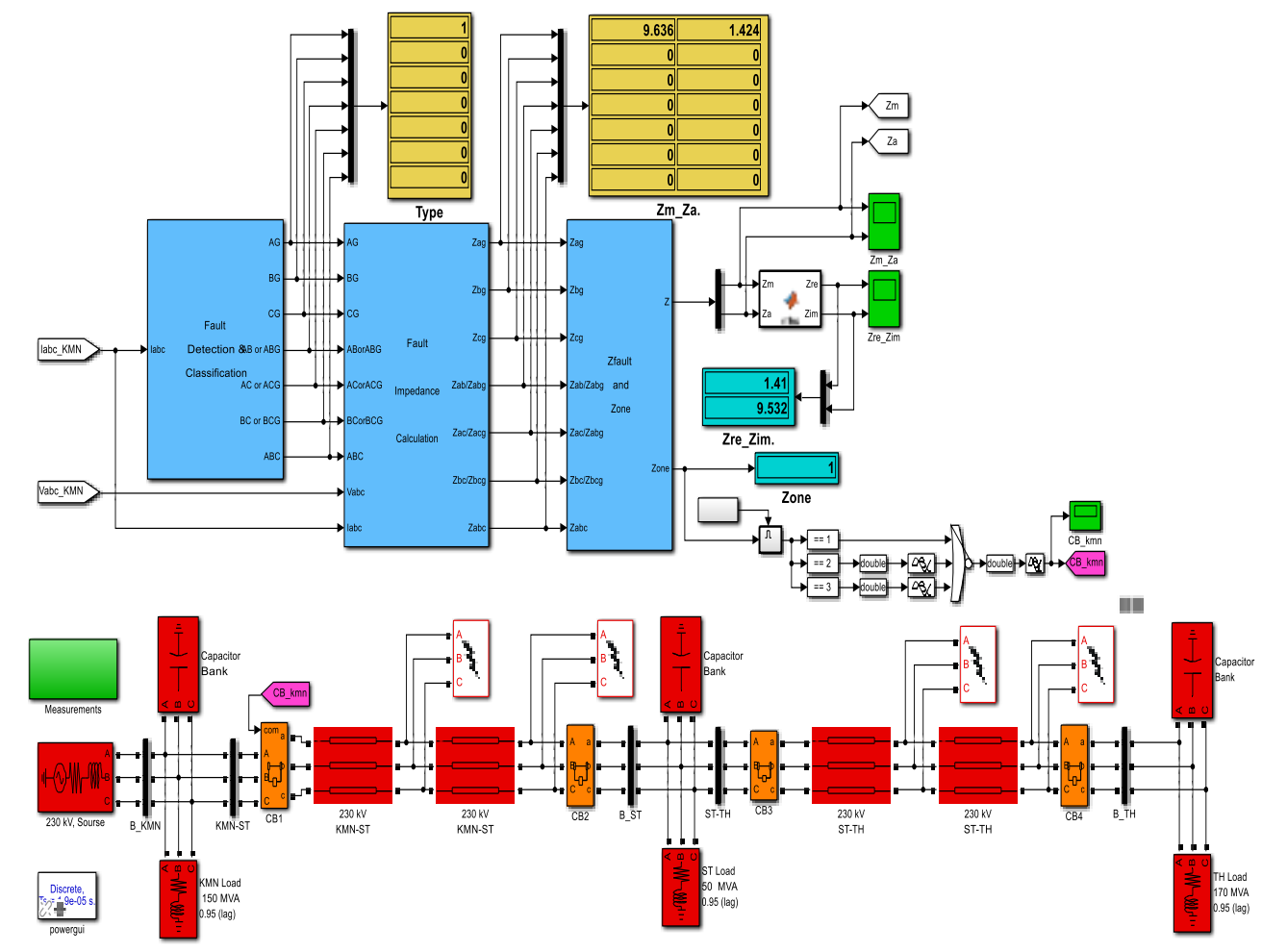

Fig. 9. Simulink Model for $230 \mathrm{kV}$ high voltage transmission line with mho type distance relay protection scheme 
Fig. 9 illustrates the operating of mho type distance relay protection scheme for selected transmission line. In this simulation, phase ' $A$ ' to ground fault is applied on KamanatSittaung transmission line. After simulation, the protection scheme displays as the fault type is A-G fault, fault impedance is $9.635 \mathrm{ohm}$ magnitude with 81.585 angle and zone of protection as ' 1 '. In all simulations, the developed system can determine the fault type, fault impedance and protection zone accurately with negligible error.

\section{Simulation Results for High Voltage Transmission LINE WITH MHO TYPE DISTANCE RELAY}

In this section, single line to ground fault, double line to ground fault, line to line fault and three phase fault are created at different locations $(30 \mathrm{~km}, 58.8 \mathrm{~km}$ and $100 \mathrm{~km})$ on the 230 $\mathrm{kV}$ transmission lines (Kamanat-Sittaung

transmission line and Sitaung-Thahtone transmission line) to study the behavior of developed mho distance relay.

For the zone of protection and fault impedance on $\mathrm{R}-\mathrm{j} X$ plain, Matlab function block with ' $m$ code' is used in simulation model of Fig. 9. In R-jX plots, the first zone, second zone and third zone protection regions are expressed with red, blue and green circles respectively. The impedance of Kamanat-Sittaung line is shown with black line. The fault impedance is indicated with magenta color asterisk at the top of red color arrow headed line.

Fig. 10 shows the impedance measured by mho type distance relay due to single line to ground fault at $30 \mathrm{~km}$ from Kamanat Bus. Moreover, Fig. 11, Fig. 12 and Fig. 13 are the impedances measured by distance relay when double line to ground fault, line to line fault and three phase fault occur at 30 $\mathrm{km}$.

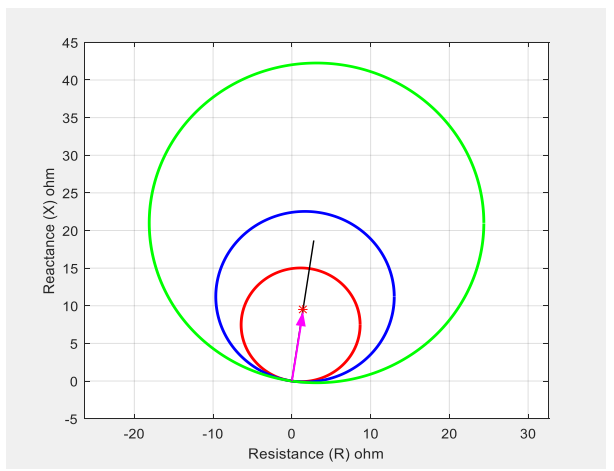

Fig. 10. R-jX plot Impedance for L-G fault at $30 \mathrm{~km}$

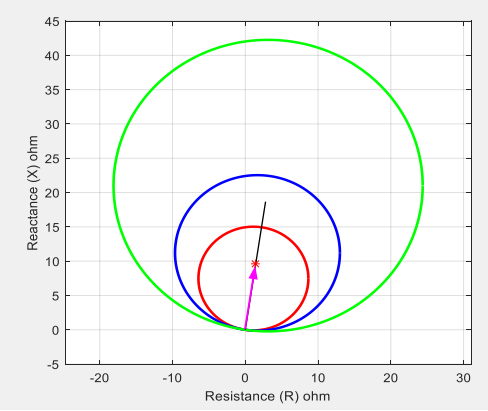

Fig. 11. R-jX plot Impedance for L-L fault at $30 \mathrm{~km}$

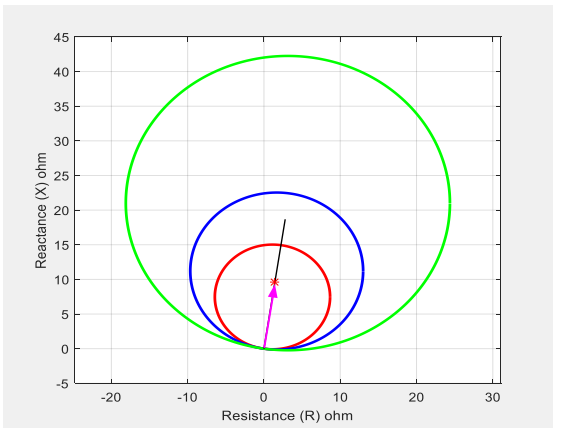

Fig. 12. R-jX plot Impedance for L-L-G fault at $30 \mathrm{~km}$

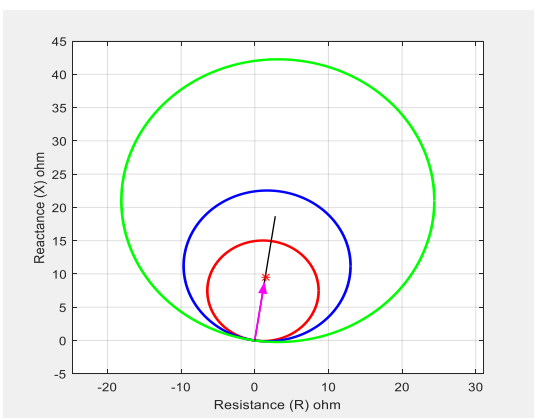

Fig. 13. R-jX plot Impedance for L-L-L fault at $30 \mathrm{~km}$

The results show that the mho type relay indicates impedance in the first zone, second zone and third zone correctly. The impedance of all of zones described R-jX plain which is correct function of relay. Various faults are created at location $58.8 \mathrm{~km}$ and $100 \mathrm{~km}$ to analyze the behavior of mho type distance relay at this types of fault. The results measured by distance relay are shown in Fig. 14, Fig. 15, Fig. 16 and Fig. 17 for distance $58.8 \mathrm{~km}$ and Fig. 18, Fig. 19, Fig. 20 and Fig. 21 for distance $100 \mathrm{~km}$ respectively. In this case, the developed mho type distance relay protection scheme can determine the fault type and protection zone correctly and accurately.

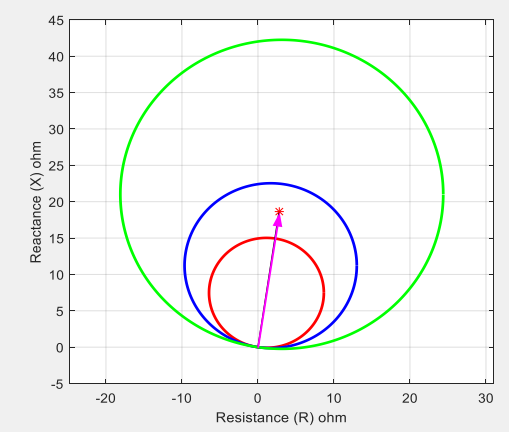

Fig. 14. R-jX plot Impedance for L-G fault at $58.8 \mathrm{~km}$

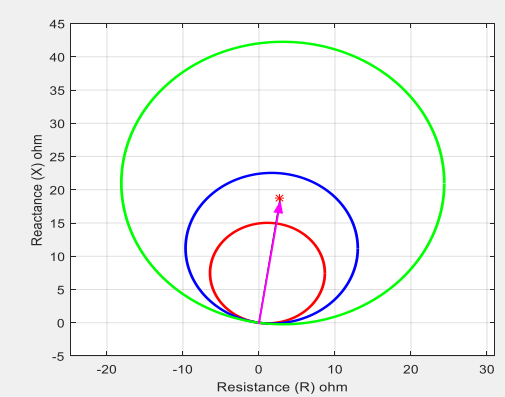

Fig. 15. R-jX plot Impedance for L-L fault at $58.8 \mathrm{~km}$ 


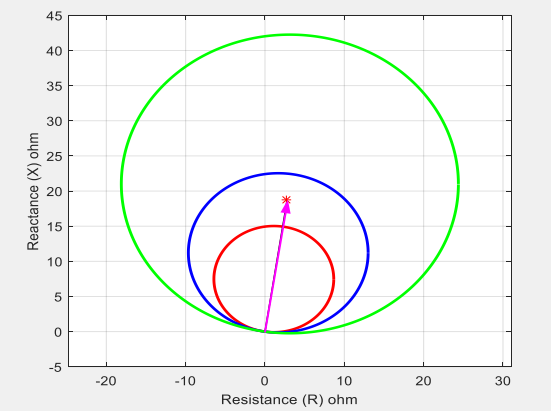

Fig. 16. R-jX plot Impedance for L-L-G fault at $58.8 \mathrm{~km}$

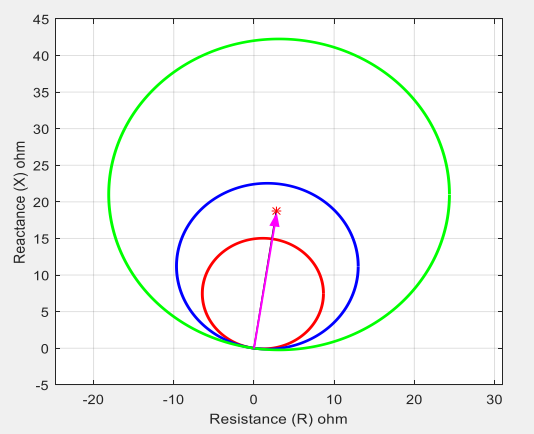

Fig. 17. R-jX plot Impedance for L-L-L fault at $58.8 \mathrm{~km}$

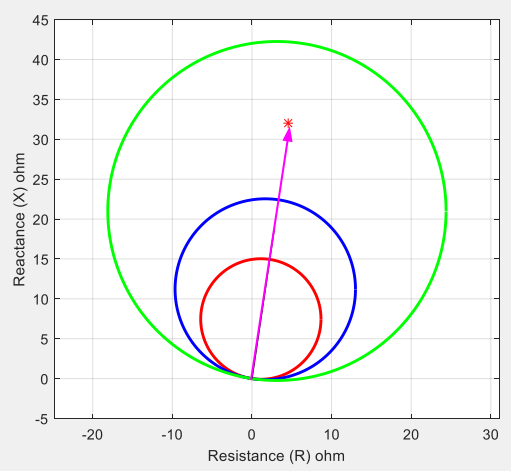

Fig. 18. R-jX plot Impedance for L-G fault at $100 \mathrm{~km}$

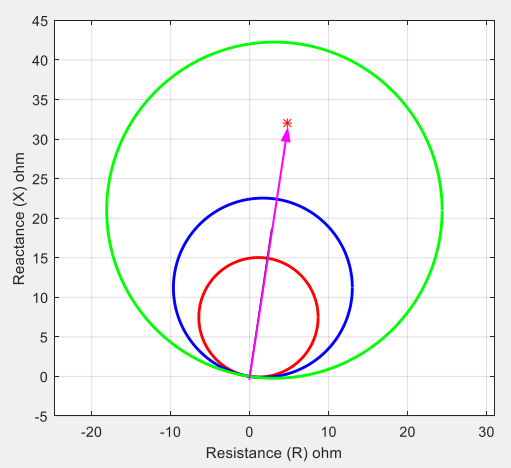

Fig. 19. R-jX plot Impedance for L-L fault at $100 \mathrm{~km}$

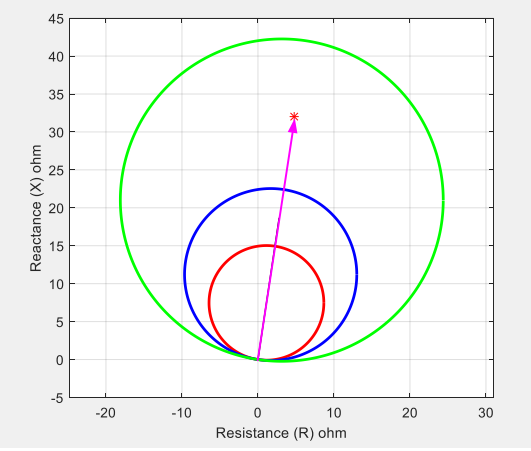

Fig. 20. R-jX plot Impedance for L-L-G fault at $100 \mathrm{~km}$

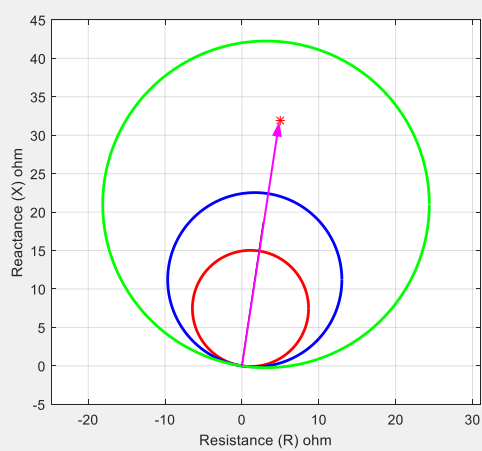

Fig. 21. R-jX plot Impedance for L-L-L fault at $100 \mathrm{~km}$

TABLE III. COMPARISON FOR ACTUAL IMPEDANCE AND MEASURED IMPEDANCE RESULTS FROM DEVELOPED MHO DISTANCE RELAY

\begin{tabular}{|c|c|c|c|c|c|c|c|}
\hline \multirow{3}{*}{ No } & \multirow{3}{*}{$\begin{array}{l}\text { Fault } \\
\text { Type }\end{array}$} & \multicolumn{6}{|c|}{ Distance $(\mathrm{km})$ from Kamanat } \\
\hline & & \multirow{2}{*}{\multicolumn{2}{|c|}{$\begin{array}{l}\text { Measured } \mathrm{Z} \text { at } 30 \\
\text { km } \\
\text { Magnitude } \mid \text { Angle } \\
\end{array}$}} & \multirow{2}{*}{\multicolumn{2}{|c|}{\begin{tabular}{|l|l} 
Measured $\mathrm{Z}$ at 58.8 \\
$\mathrm{~km}$
\end{tabular}}} & \multirow{2}{*}{\multicolumn{2}{|c|}{\begin{tabular}{|l|}
$\begin{array}{l}\text { Measured } \mathrm{Z} \text { at } 10 \mathrm{C} \\
\text { km }\end{array}$ \\
Magnitude Angle \\
\end{tabular}}} \\
\hline & & & & & & & \\
\hline 1 & A-G & 9.635 & 81.585 & 18.895 & 81.533 & 32.371 & 81.919 \\
\hline 2 & A-B & 9.670 & 81.796 & 18.989 & 81.907 & 32.364 & 81.508 \\
\hline 3 & A-B-G & 9.670 & 81.796 & 18.989 & 81.907 & 32.364 & 81.508 \\
\hline 4 & A-B-C & 9.640 & 81.289 & 18.909 & 81.457 & 32.249 & 81.086 \\
\hline$A$ & dal Z & 9.440 & 81.511 & 18.881 & 81.511 & 32.111 & 81.511 \\
\hline
\end{tabular}

Table III shows the simulation results for high voltage transmission lines with developed mho type distance relay. The actual impedances for zone 1, zone 2 and zone 3 at $30 \mathrm{~km}, 58.8$ $\mathrm{km}$ and $100 \mathrm{~km}$ are $9.440 \mathrm{ohm}$ magnitude with 81.511 angle, $18.8 \mathrm{ohm}$ magnitude with 81.511 angle and 32.111 magnitude with 81.511 angle. The various faults such as single line to ground (L-G) fault, double line to ground (L-L) fault, line to line (L-L) fault and three phase (L-L-L) fault were created in high voltage transmission line with the developed mho type distance relay and the results are analyzed. When the simulation results for zone 1 ,zone 2 and zone 3 are compared with the actual value of zone 1 , zone 2 and zone 3 , the simulation results nearly equal the actual values. Therefore, the developed mho type distance relay operated as per the theoretical characteristic.

\section{CONCLUSION}

The mho type distance relay was successfully modeled and simulated by using MATLAB/SIMULINK software. The simulation results show that software was capable to be used for modeling and simulation of any type of relay such as overcurrent and earth fault relay, over or under voltage relay 
and differential relay, etc. The function for mho type distance relay was created by using special blocks of MATLAB/SIMULINK. By studying the behavior of the developed mho type distance relay model at different location of transmission line, the relay model was able to operate the appropriate fault types correctly. Moreover, this relay indicates correct zone of operation in all cases. When fault locations change, the relay identifies correct zones and the measured impedance changes depend on fault locations and the value of fault currents. From R-X plain, the simulation results show that the characteristics of mho type distance relay operate as per theoretical characteristic.

\section{ACKNOWLEDGMENT}

The authors would like to thanks the department of electrical power engineering and Yangon Technological University (YTU) for supporting. The authors wish to express thanks to their teachers who gave suggestions, discussion and ideas.

\section{REFERENCES}

[1] DibyaDarshiniM0hanty, AshwinSharwin Sharma, AshutoshVarma, "Performance assessment of distance relay using matlab," International Journal of Engineering Research and Technology (IJERT), vol. 2, 2 Issue 12, December. 2013.

[2] J.N.Rai,Aquib Jahangir, IlamHoque, "Digital simulation of distance relay for long transmission line," 2017 4th IEEE Uttar Pradesh Section International Conference on Electrical, Computer and Electronics (UPCON), GLA University, Mathura,Oct 26028, 2017.

[3] PurraSaiKiran, P.Ramchander, "Modeling and performance analysis of mho relay in matlab," International Journal and Magazine of Engineering, Technology, Management and research, Volume No:2(2015), Issue No:1(January), January 2015.

[4] Mr.Kunal, K.Joshi, Prof. M.R.Hans, "Development of mho type distance relay for protection of long transmission line using matlab/simulink environment," International Journal of Engineering Research and Technology (IJERT), vol. 5, Issue 04,April.2016.

[5] M.Rambabu, M.Venkatesh, J.S.V.SivaKumar,T.S.L.V.AyyaRao, "Three zone protection by using distance relays in simulink/matlab", International Research Journal of Engineering and Technology (IRJET), vol. 02, Issue. 05, Aug. 2015.

[6] JayantLamture, A.P.Vaidya, "Development of distance relay in matalb," International Journal of Advanced Computational Engineering and Networking, ISSN:2320-2016, vol. 3, Issue 9, Sept. 2015. 